\title{
STUDI KOMPARASI PENERAPAN METODE TRADISIONAL DAN METODE ACTIVITY BASED COSTING SEBAGAI ALTERNATIF PENENTUAN BIAYA SATUAN PENDIDIKAN PADA SD ISLAM AT TAQWA BEKASI TAHUN AJARAN 2018/2019
}

\author{
Baiq Farah Pratiwi \\ baiqfarahpratiwi@gmail.com \\ Yusep Friya P. S \\ yosep.friya@akuntansi.pnj.ac.id \\ Novitasari \\ novitasari26@gmail.com \\ Program Studi Akuntansi Keuangan Terapan Politeknik Negeri Jakarta
}

\begin{abstract}
The purpose of this study is to determine the calculation of the educational unit cost that are calculated using traditional methods, determine the calculation of the educational unit cost that are calculated using activity based costing method, and to know the comparison of costs calculated using both methods. This research uses a quantitative case study method with a descriptive approach. Data collection methods used to obtain data are by interview, documentation and observation. The results of this study indicate that the unit cost of education at SD Islam At-taqwa academic year 2018/2019 which is calculated using the activity based costing method is not always higher or lower than traditional method calculations. This shows the distortion in the form of undercosting and overcosting in the calculation of the educational unit cost due to the calculation of the comparison of educational unit cost using traditional method and the activity based costing method.
\end{abstract}

Keywords: Educational Unit Cost, Traditional Method, Activity Based Costing Method

\begin{abstract}
ABSTRAK
Tujuan penelitian ini adalah untuk mengetahui perhitungan biaya satuan pendidikan yang dihitung menggunakan metode tradisional, mengetahui biaya satuan pendidikan yang dihitung menggunakan metode activity based costing, dan mengetahui komparasi biaya yang dihitung menggunakan kedua metode tersebut. Penelitian ini menggunakan metode kuantitatif studi kasus dengan pendekatan deskriptif. Metode pengumpulan data yang dilakukan untuk memperoleh data adalah dengan wawancara, dokumentasi dan observasi. Hasil penelitian ini menunjukkan bahwa biaya satuan pendidikan yang SD Islam At-taqwa yang dihitung menggunakan metode activity based costing tidak selalu lebih tinggi ataupun lebih rendah dari perhitungan metode tradisional. Hal ini menunjukan adanya distorsi berupa undercosting dan overcosting dalam perhitungan biaya satuan pendidikan dikarenakan adanya perhitungan perbandingan biaya satuan pendidikan menggunakan metode tradisional dan metode activity based costing.
\end{abstract}

Kata kunci: Biaya Satuan Pendidikan, Metode Tradisional, Metode Activity Based Costing.

\section{PENDAHULUAN \\ Latar Belakang}

Pendidikan dan manusia merupakan hal yang tidak dapat dipisahkan, tidak ada pendidikan tanpa manusia dan tidak ada manusia tanpa pendidikan, hal ini diungkapkan oleh Kadir (2015), beliau juga menambahkan bahwa Pendidikan yang berkualitas merupakan suatu kebutuhan primer bagi manusia yang digunakan untuk mengembangkan diri. Kualitas pendidikan tentu tidak luput dari perencanaan, pengelolaan, dan pengawasan dana pendidikan suatu negara (Dewi, 2018) Perencanaan dana pendidikan merupakan suatu proyeksi tentang apa yang harus dilaksanakan, yang memiliki unsur kegiatan mengidentifikasi sampai dengan menyeleksi kebutuhan berdasarkan skala prioritas, mengadakan spesifikasi yang lebih terperinci mengenai hasil dan tujuan yang ingin dicapai, dan unsur lainnya (Somantri, 2014). 
Sebagaimana telah diatur dalam Undang Undang Dasar 1945 Pasal 31 ayat (4) bahwa negara diwajibkan memprioritaskan dana pendidikan sekurang-kurangnya 20 persen dari Anggaran Pendapatan dan Belanja Nasional (APBN), dan diatur dalam Peraturan Daerah Kota Bekasi No. 13 Tahun 2014 ayat (4) selain gaji pendidik dan biaya pendidikan kedinasan dialokasikan minimal 20 persen dari Anggaran Pendapatan dan Belanja Daerah (APBD). Pemerintah pusat, pemerintah daerah sampai dengan lini sekolah harus bersamasama mengelola anggaran pendidikan tersebut guna menunjang sarana pendidikan di Indonesia yang berkualitas (Bastian \& Idrus, 2014). Sekolah diwajibkan membuat perencanaan dana pendidikan dalam bentuk Rencana Kegiatan dan Anggaran Sekolah atau RKAS yang harus dirincikan seakurat mungkin (Tanggela, 2013).

Dapat disimpulkan bahwa sekolah sebagai organisasi yang bersentuhan langsung dengan masyarakat. Maka sekolah mempunyai tanggung jawab atas dana yang dikelolanya, dengan melakukan analisis terhadap dana tersebut, baik yang berasal dari pemerintah, swasta, maupun sumbangan orang tua siswa, analisis ini dilakukan agar sekolah dapat mengetahui ada tidaknya pemborosan atau ketidaksesuaian dana yang diberikan dengan keadaan pada operasional sekolah (Azizah \& Sukirno, 2016).

Menurut Dwi (2018), biaya pendidikan perlu dihitung dalam skala Biaya Satuan (unit cost) sehingga dapat diketahui secara akurat untuk menyelenggarakan program pendidikan khususnya pada tingkat Sekolah Dasar (SD).

SD Islam At Taqwa Bekasi
merupakan sekolah
mengimplementasikan konsep pendidikan islam berdasarkan Al-Quran dan Sunnah secara menyeluruh, yang artinya bukan hanya mengajarkan nilai-nilai formal, namun juga nilai-nilai pada kehidupan sehari-hari para siswa didiknya. SD Islam At Taqwa memperoleh dana pendidikan dari Bantuan Operasional Sekolah Nasional (BOSNAS), Bantuan Operasional Sekolah Daerah (BOSDA), Uang Pembangunan (UP), Sumbangan Pelaksanaan Pendidikan (SPP), sumbangan orangtua murid, dan sumber dana yang sah lainnya. Penentuan jumlah uang iuran SPP ditentukan oleh pihak yayasan. Dengan metode tersebut, penentuan jumlah SPP dianggap belum akurat dan kurang transparan.
Pada penelitian ini penulis membandingkan dua metode yang sekiranya dapat dipertimbangkan menjadi metode penentuan biaya satuan pendidikan di SDI Attaqwa Bekasi. Salah satu metode yang efektif dan efisien adalah dengan menghitung biaya berdasarkan aktivitas atau Activity Based Costing (ABC). Metode ABC akan memperbaiki perhitungan biaya dengan mengidentifikasi aktivitas individu sebagai objek dasar. Perbedaan utama penggunaan Activity based costing dengan metode tradisional adalah cost driver (pemicu biaya) yang digunakan dalam Activity Based Costing lebih beragam dibandingkan dengan metode tradisional.

Apabila sekolah mampu untuk menghitung biaya satuan (unit cost) dengan akurat dan dapat menyajikan biaya secara transparan, akuntabel, dan valid atas unit cost yang benar-benar terjadi di sekolah, maka semua pihak khususnya pemerintah pusat, pemerintah daerah, masyarakat, maupun bagian keuangan sekolah itu sendiri mampu memanfaatkan informasi tersebut sebagai dasar pengambilan keputusan strategis jangka pendek, menengah, maupun panjang secara efektif.

\section{Permasalahan}

Berdasarkan permasalahan pada latar belakang, maka rumusan masalah yang akan diteliti pada penelitian ini adalah:

1. Berapa biaya satuan pendidikan per siswa SD Islam At Taqwa Bekasi tahun ajaran 2018/2019 yang dihitung menggunakan metode tradisional?

2. Berapa biaya satuan pendidikan per siswa SD Islam At Taqwa Bekasi tahun ajaran 2018/2019 yang dihitung menggunakan metode activity based cost?

3. Bagaimana komparasi perhitungan biaya satuan pendidikan yang dihitung menggunakan metode tradisional dan metode Activity Based Cost?

\section{Tujuan}

Merujuk pada permasalahan dan pertanyaan penelitian, penelitian ini bertujuan untuk:

1. Untuk mengetahui berapa biaya satuan pendidikan per siswa SD Islam At Taqwa Bekasi tahun ajaran 2018/2019 yang dihitung dengan menggunakan metode tradisional 
2. Untuk mengetahui berapa biaya satuan pendidikan per siswa SD Islam At Taqwa Bekasi tahun ajaran 2018/2019 yang dihitung dengan menggunakan metode activity based cost

3. Untuk mengetahui perbedaan yang terjadi antara perhitungan biaya satuan pendidikan menggunakan metode tradisional dan metode activity based cost

\section{TINJAUAN PUSTAKA \\ Biaya Pendidikan}

Biaya pendidikan dapat diartikan sebagai biaya yang timbul dari aktivitas utama pendidikan yang dikeluarkan oleh pihak yang terlibat dalam kegiatan pendidikan, yang sifatnya tidak terhindarkan, dan sudah diperhitungnkan dalam bentuk uang dalam harga yang berlaku.

\section{Biaya Satuan Pendidikan}

Biaya satuan pendidikan adalah biaya rata-rata siswa pertahunnya, yang dapat menunjang proses belajar mengajar sesuai dengan pelayanan yang telah ditentukan.

\section{Metode Tradisional}

Menurut Slamet (2016) perhitungan metode tradisional adalah perhitungan yang hanya membebankan biaya produksi pada produk, biaya produk biasanya dimonitor dari tiga komponen biaya yaitu bahan baku, tenaga kerja langsung, dan overhead pabrik, sehingga pembebanan biayanya dialokasikan kepada jumlah produk, yang pada penelitian ini adalah jumlah siswa.

\section{Metode Activity Based Costing}

Menurut Bastian (2015), Perhitungan biaya berdasarkan aktivitas yang didasarkan pada konsep pelayanan pendidikan yang mengkonsumsi aktivitas dan aktivitas yang mengkonsumsi sumberdaya organisasi pelayanan pendidikan. Metode activity based costing juga dapat didefiniskan sebagai perhitungan biaya yang dalam pembebannya biayanya didasarkan oleh aktivitas. Pembebanan dengan dasar aktivitas tersebut, kemudian dibebankan dengan dasar penggerak biaya (cost driver).

\section{METODE PENELITIAN Jenis Penelitian}

Penelitian yang dilakukan oleh penulis menggunakan penelitian deskriptif dengan pendekatan kuantitatif. Penelitian deskriptif bertujuan untuk menggambarkan atau mendefinisikan apa saja yang terlibat dalam suatu kegiatan, apa yang dilakukan, dan bagaimana cara melakukannya. Penelitian deskriptif tidak dimaksudkan untuk menguji hipotesis tetapi hanya menggambarkan apa adanya tentang keadaan suatu variabel, gejala dan keadaannya.

\section{Objek Penelitian}

Dalam penelitian ini, penulis memusatkan penelitiannya pada SD Islam Attaqwa Bekasi, dengan objek penelitian unit cost atau biaya pendidikan per siswa per tingkat di SDI At-taqwa Bekasi tahun ajaran 2018/2019.

\section{Jenis Data dan Sumber Data}

Data penelitian ini menggunakan data primer dan sekunder. Data primer didapatkan penulis dari hasil observasi, wawancara dan dokumentasi dengan sampel terkait dengan topik penelitian. Sedangkan data sekunder adalah data pengenai Peraturan pemerintah, peraturan daerah, dan data lainnya.

\section{Metode Pengumpulan Data}

Penelitian ini melakukan pengumpulan data dengan metode observasi, wawancara, dan juga dokumentasi. Penulis melakukan observasi dengan cara mengamati kegiatan yang ada di SD Islam At Taqwa Bekasi tanpa berpartisipasi kedalam bagian kegiatan tersebut (non-participant observer). Wawancara dilakukan penulis dengan sampel yang mempunyai informasi terkait topik penelitian seperti data RKAS, sarana prasarana, data jumlah siswa, jumlah guru, jumlah jam efektif, dan data pendukung lainnya. Penulis juga melakukan dokumentasi yang berasal dari jurnal, buku, internet, dan data yang diperoleh langsung dari objek penelitian yaitu SD Islam At Taqwa Bekasi.

\section{Analisis Data}

Teknik analisis data dalam penelitian ini adalah untuk mengetahui biaya satuan pendidikan dengan menganalisa dan keuangan SDI At-taqwa Bekasi Tahun Ajaran 2018/2019. Adapun langkah-langkah dalam penelitian ini adalah sebagai berikut:

\section{Metode tradisional}

Analisa data dengan metode tradisional dilakukan dengan cara:

a. Pengidentifikasian Objek Biaya 
Objek biaya dalam penelitian ini adalah aktivitas yang ada dalam Rancana Kerja dan Anggaran SD Islam At Taqwa Bekasi. Unsur aktivitas yang dapat menjadi objek biaya adalah berdasarkan unit, berdasarkan batch, dan berdasarkan fasilitas.

b. Pengidentifikasian Biaya

Biaya dapat diidentifikasi menjadi biaya utama, biaya tenaga kerja, dan biaya overhead. Setelah diidentifikasi, biaya-biaya tersebut dapat digolongkan menjadi biaya langsung dan tidak langsung.

c. Penentuan dasar-dasar alokasi biaya Biaya Overhead akan dialokasikan langsung ke jumlah siswa. Sedangkan biaya utama terdiri dari biaya langsung dan biaya tidak langsung. Dasar dasar alokasi biaya tidak langsung dapat berupa Jumlah siswa kelas I sampai dengan kelas VI, jumlah tingkat kelas, jumlah rombongan belajar, dan jumlah jam efektif.

d. Menghitung biaya overhead Biaya overhead adalah biaya yang harus terjadi meskipun secara langsung tidak berhubungan dengan proses produksi, yang digolongkan selain dari biaya utama dan biaya tenaga kerja (Purwaji, Wibowo, \& Muslim, 2016). Perhitungan biaya overhead dapat dilakukan dengan cara:

$$
\text { Tarif } \text { overhead }=\frac{\text { Total biaya overhead }}{\text { Jumlah siswa }}
$$

e. Menghitung biaya utama per unit Biaya utama berasal dari aktivitas pokok yaitu kegiatan belajar mengajar dan aktivitas yang ada pada bidang kesiswaan.

f. Menghitung biaya tenaga kerja per unit

Biaya yang terjadi atas gaji pegawai, baik yang tetap maupun kontrak, dengan pemicu jam efektif dalam satu tahun.

g. Perhitungan satuan biaya pendidikan menggunakan metode tradisional

\section{Metode Activity Based Cost}

Analisa data dengan metode activity based costing dilakukan dengan cara sebagai berikut: a. Identifikasi dan penggolongan aktivitas

Hal ini dilakukan dengan cara Mengidentifikasi aktivitas yang dilakukan di SD Islam At Taqwa Bekasi, kemudian mengidentifikasi semua sumber daya yang digunakan oleh SD Islam At Taqwa Bekasi baik berupa dana (uang), tenaga kerja, maupun sarana prasarana, jumlah guru, jumlah siswa. Kemudian aktivitas-aktivitas tersebut akan diklasifikasikan menjadi dua, yakni aktivitas utama dan aktivitas penunjang serta digolongan sesuai dengan karakteristik masing-masing aktivitas (Result Producing Activities, Result Contributing Activities, dan Support Activities).

b. Pembebanan biaya ke aktivitas dan pembebanan biaya antar aktivitas Biaya yang telah terkumpul ke berbagai aktivitas baik aktivitas langsung (utama) maupun aktivitas tidak langsung (pendukung) diidentifikasi kembali apabila terdapat biaya untuk antar-aktivitas, baik antar-aktivitas pendukung ataupun dari aktivitas pendukung ke aktivitas utama.

c. Pengumpulan biaya dalam cost pool Selanjutnya seluruh biaya yang telah dialokasikan ke dalam aktivitas utama akan diidentifikasi kembali karakteristiknya untuk mempermudah pembebanannya ke masing-masing tingkat dan kompetensi keahlian untuk memperoleh driver yang tepat. Biaya yang memiliki karakteristik dan driver yang sama akan dikelompokkan ke dalam activity cost pool.

d. Identifikasi dan perhitungan cost driver

Pada tahap ini, biaya diidentifikasi cost driver-nya dengan cara menganalisa jumlah siswa, luas ruangan, jumlah guru, pemakaian daya, dan lain-lain. Kemudian membebankan biaya cost object sesuai dengan besarnya biaya yang dikonsumsi dengan melihat cost driver tersebut. Sehingga akan diperoleh tarif cost driver per unit sebagai berikut: 
Tarif per unit $=\frac{\text { cost object }}{\text { Unit cost driver }}$

e. Penentuan biaya satuan pendidikan SD Islam At Taqwa Bekasi dengan metode activity based cost

Selanjutnya biaya yang telah diidentifikasi kemudian dialokasikan untuk menghasilkan biaya yang dikonsumsi oleh masing-masing tingkat dan jurusan dengan menggunakan cost driver yang telah dihitung sebelumnya. Biaya yang dikonsumsi masing-masing tingkat dan jurusan akan dihitung untuk menentukan biaya satuan pendidikan dengan cara membagi nilai tersebut dengan jumlah siswa.

3. Komparasi perhitungan biaya satuan pendidikan menggunakan metode tradisional dan metode activity based costing

Pada tahap ini, akan dilakukan perbandingan antara hasil perhitungan biaya satuan pendidikan menggunakan metode tradisional dan metode activity based costing. Menghitung apakah terjadi undercost dan overcost terhadap perhitungan tradisional dengan cara mencari selisih dari hasil perhitungan kedua metode.

\section{HASIL DAN PEMBAHASAN \\ Hasil Perhitungan Biaya Satuan Pendidikan Dengan Menggunakan Metode Tradisional \\ Biaya satuan pendidikan} menggunakan metode tradisional (dalam satuan rupiah)

\begin{tabular}{|c|c|c|c|c|c|c|c|c|c|c|c|c|c|c|}
\hline \multirow{2}{*}{ No } & \multirow{2}{*}{ Aktivitas } & \multirow{2}{*}{ Biaya Per Unit } & \multicolumn{2}{|r|}{ Kelas I } & \multicolumn{2}{|r|}{ Kelas II } & \multicolumn{2}{|r|}{ Kelas III } & \multicolumn{2}{|r|}{ Kelas IV } & \multicolumn{2}{|r|}{ Kelas V } & \multicolumn{2}{|r|}{ Kelas VI } \\
\hline & & & $\mathbf{Q}$ & Biaya & $\mathbf{Q}$ & Biaya & $\mathbf{Q}$ & Biaya & $\mathbf{Q}$ & Biaya & $\mathbf{Q}$ & Biaya & $\mathbf{Q}$ & Biaya \\
\hline $\mathbf{A}$ & \multicolumn{14}{|c|}{ BIAYA UTAMA } \\
\hline \multicolumn{15}{|c|}{1 Kegiatan Belajar Mengajar } \\
\hline & \begin{tabular}{|l|l|}
$\mathrm{a}$ & $\begin{array}{l}\text { Pengadaan Bahan } \\
\text { Praktek (Kelas } \\
\text { III,IV,V,VI) }\end{array}$ \\
\end{tabular} & 243.750 & & & & & 1 & 243.750 & 1 & 243.750 & 1 & 243.750 & 1 & 243.750 \\
\hline & \begin{tabular}{|l|l|}
$\mathrm{b}$ & $\begin{array}{l}\text { Kegiatan Antar } \\
\text { Rombongan } \\
\text { Belajar }\end{array}$ \\
\end{tabular} & 12.801 .000 & 1 & 12.801 .000 & 2 & 25.602 .000 & 1 & 12.801 .000 & 1 & 12.801 .000 & 1 & 12.801 .000 & 1 & 12.801 .000 \\
\hline & \begin{tabular}{|l|l|}
$\mathrm{c}$ & $\begin{array}{l}\text { Kegiatan Seluruh } \\
\text { Siswa }\end{array}$ \\
\end{tabular} & 161.555 & 23 & 3.715 .756 & 29 & 4.685 .084 & 16 & 2.584 .874 & 18 & 2.907 .983 & 19 & 3.069 .538 & 14 & 2.261 .765 \\
\hline & \begin{tabular}{|l|l}
$\mathrm{d}$ & $\begin{array}{l}\text { Kegiatan Khusus } \\
\text { Kelas VI }\end{array}$ \\
\end{tabular} & 289.143 & & & & & & & & & & & 14 & 4.048 .000 \\
\hline \multicolumn{15}{|c|}{\begin{tabular}{|l|l|}
2 & Kegiatan Kesiswaan \\
\end{tabular}} \\
\hline & \begin{tabular}{|l|l|} 
a & $\begin{array}{l}\text { Kegiatan Seluruh } \\
\text { Siswa }\end{array}$ \\
\end{tabular} & 48.613 & 23 & 1.118 .109 & 29 & 1.409 .790 & 16 & 777.815 & 18 & 875.042 & 19 & 923.655 & 14 & 680.588 \\
\hline & \begin{tabular}{|l|l}
$\mathrm{b}$ & $\begin{array}{l}\text { Kegiatan Khusus } \\
\text { Kelas I }\end{array}$ \\
\end{tabular} & 313.880 & 23 & 7.219 .231 & & & & & & & & & & \\
\hline & \begin{tabular}{|l|l|} 
c & $\begin{array}{l}\text { Kegiatan Khusus } \\
\text { Kelas II }\end{array}$ \\
\end{tabular} & 66.844 & & & 29 & 1.938 .462 & & & & & & & & \\
\hline & \begin{tabular}{|l|l|}
$\mathrm{d}$ & $\begin{array}{l}\text { Kegiatan Khusus } \\
\text { Kelas III }\end{array}$ \\
\end{tabular} & 121.154 & & & & & 16 & 1.938 .462 & & & & & & \\
\hline & \begin{tabular}{|l|l|} 
e & Kegiatan Khusus \\
Kelas IV
\end{tabular} & 215.385 & & & & & & & 18 & 3.876 .923 & & & & \\
\hline & \begin{tabular}{|l|l|}
$\mathrm{f}$ & $\begin{array}{l}\text { Kegiatan Khusus } \\
\text { Kelas V V }\end{array}$ \\
\end{tabular} & 204.049 & & & & & & & & & 19 & 3.876 .923 & & \\
\hline & $\begin{array}{l}\mathrm{g} \mid \begin{array}{l}\text { Kegiatan Khusus } \\
\text { Kelas VI }\end{array} \\
\end{array}$ & 60.000 & & & & & & & & & & & 14 & 840.000 \\
\hline $\mathbf{B}$ & \multicolumn{14}{|c|}{ BIAYA TENAGA KERJA } \\
\hline & \begin{tabular}{l|l}
$\mathrm{a}$ & $\begin{array}{l}\text { Gaji Guru Tetap \& } \\
\text { Tidak Tetap }\end{array}$ \\
\end{tabular} & 19.806 & 2256 & 44.681 .720 & 4512 & 89.363 .439 & 2350 & 46.543 .458 & 2726 & 53.990 .411 & 2726 & 53.990 .411 & 2301 & 45.572 .977 \\
\hline $\mathbf{C}$ & \multicolumn{14}{|l|}{ BOP } \\
\hline & \begin{tabular}{|l|l|}
$\mathrm{b}$ & PS, SDM, ADM, \\
MNJ, SarPras, \\
Tendik, Jasa Daya
\end{tabular} & 2.930 .913 & 23 & 67.411 .006 & 29 & 84.996 .486 & 16 & 46.894 .613 & 18 & 52.756 .439 & 19 & 55.687 .353 & 14 & 41.032 .786 \\
\hline \multicolumn{3}{|c|}{ Jumlah Biaya } & & 136.946 .822 & & 207.995 .261 & & 111.783 .971 & & 127.451 .549 & & 130.592 .630 & & 107.480 .867 \\
\hline \multicolumn{3}{|c|}{ Jumlah Siswa Per tingkat } & & 23 & & 29 & & 16 & & 18 & & 19 & & 14 \\
\hline \multicolumn{3}{|c|}{ Biaya Persiswa Pertahun } & & 5.954 .210 & & 7.172 .250 & & 6.986 .498 & & 7.080 .642 & & 6.873 .296 & & 7.677 .205 \\
\hline \multicolumn{3}{|c|}{ Biaya Per siswa Per bulan } & & 496.184 & & 597.688 & & 582.208 & & 590.053 & & 572.775 & & 639.767 \\
\hline
\end{tabular}

Sumber: Data diolah

paling banyak diantara semua tingkat kelas. Kemudian, kelas I adalah tingkatan yang mempunyai biaya kesluruhan tertinggi setelah

Dari tabel di atas kita bisa mengetahui bahwa jumlah biaya keseluruhan per tahun tingkat kelas II adalah biaya yang paling tinggi apabila dibandingkan dengan kelas lainnya, hal ini disebabkan karena jumlah siswa di tingkat kelas II adalah jumlah siswa yang kelas II, padahal dibandingkan dengan kelas lain, kelas ini adalah kelas yang mempunyai aktivitas khusus paling sedikit, hal ini disebabkan karena dalam metode tradisional, biaya dialokasikan bukan berdasarkan aktivitas melainkan dialokasikan ke jumlah 
siswa, oleh karena itu biaya kesuluruhan kelas I tinggi dikarenakan jumlah siswa yang lebih banyak dari kelas III, IV, V, dan VI.

Kemudian juga dapat disimpulkan bahwa biaya satuan pendidikan per bulan kelas VI merupakan angka yang paling tinggi meskipun pada grafik biaya keseluruhan per tahun kelas VI bukan kelas yang memiliki biaya paling tinggi. Hal ini disebabkan karena dalam biaya tradisional untuk menghitung biaya satuan pendidikan dilakukan dengan cara membagi jumlah biaya keseluruhan dengan jumlah siswa pada tingkat tersebut, sehingga biaya satuan pendidikan yang tinggi disebabkan karena jumlah siswa di kelas VI merupakan jumlah yang paling sedikit, yaitu 14 siswa. Hal ini juga berlaku di kelas I, meskipun biaya keseluruhannya tingg, karena jumlah siswa di kelas I merupakan jumlah yang paling banyak setelah kelas II, maka biaya satuan pendidikannya menjadi rendah.

\section{Hasil Perhitungan Biaya Satuan Pendidikan Dengan Menggunakan Metode Activity Based Costing}

Hasil perhitungan biaya satuan pendidikan SDI At-taqwa Bekasi tahun ajaran 2018/2019 dengan menggunakan metode activity based costing. (dalam satuan rupiah)

\begin{tabular}{|c|c|c|c|c|c|c|c|c|c|c|c|c|c|c|}
\hline \multirow{2}{*}{ No } & \multirow{2}{*}{ Aktivitas } & \multirow{2}{*}{ Cost Driver } & \multicolumn{2}{|r|}{ Kelas I } & \multicolumn{2}{|c|}{ Kelas II } & \multicolumn{2}{|c|}{ Kelas III } & \multicolumn{2}{|c|}{ Kelas IV } & \multicolumn{2}{|c|}{ Kelas V } & \multicolumn{2}{|c|}{ Kelas VI } \\
\hline & & & AD & ADR & AD & ADR & AD & ADR & AD & ADR & AD & ADR & AD & ADR \\
\hline \multirow{6}{*}{ 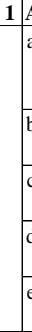 } & Aktivitas KBM & & & & & & & & & & & & & \\
\hline & \begin{tabular}{|l|l|} 
a & Activity Cost Pool KBM \\
antar Rombel (Kelas \\
III,IV,VVI)
\end{tabular} & 243.750 & & & & & 1 & 243.750 & 1 & 243.750 & 1 & 243.750 & 1 & 243.750 \\
\hline & \begin{tabular}{|l|l}
$\mathrm{b}$ & $\begin{array}{l}\text { Activity Cost Pool KBM } \\
\text { antar Rombel }\end{array}$
\end{tabular} & 12.801 .000 & 1 & 12.801 .000 & 2 & 25.602 .000 & 1 & 12.801 .000 & 1 & 12.801 .000 & 1 & 12.801 .000 & 1 & 12.801 .000 \\
\hline & \begin{tabular}{|l|l|} 
c & $\begin{array}{l}\text { Activity Cost Pool KBM } \\
\text { Seluruh Siswa }\end{array}$ \\
\end{tabular} & 161.555 & 23 & & 29 & & 16 & & 18 & & 19 & & 14 & \\
\hline & \begin{tabular}{|l|l|}
$\mathrm{d}$ & $\begin{array}{l}\text { Activity Cost Pool KBM } \\
\text { khusus Kelas VI }\end{array}$ \\
\end{tabular} & 289.143 & & & & & & & & & & & & \\
\hline & \begin{tabular}{|l|l|} 
e & $\begin{array}{l}\text { Activity Cost Pool KBM } \\
\text { Berdasarkan Aktivitas }\end{array}$ \\
\end{tabular} & 34.491 & 2256 & 77.811 .637 & 4512 & 155.623 .274 & 2350 & 81.053 .789 & 2350 & 81.053 .789 & 2726 & 94.022 .395 & 2301 & 79.363 .731 \\
\hline \multirow[t]{9}{*}{2} & Aktivitas Kesiswaan & & & & & & & & & & & & & \\
\hline & \begin{tabular}{|l|l} 
a & $\begin{array}{l}\text { Activity Cost Pool KBM } \\
\text { khusus Kelas I }\end{array}$
\end{tabular} & 313.880 & 23 & 7.219 .230 & & & & & & & & & & \\
\hline & \begin{tabular}{|l|l}
$\mathrm{b}$ & $\begin{array}{l}\text { Activity Cost Pool KBM } \\
\text { khusus Kelas II }\end{array}$ \\
\end{tabular} & 66.844 & & & 29 & 1.938 .462 & & & & & & & & \\
\hline & \begin{tabular}{|l|l|} 
c & $\begin{array}{l}\text { Activity Cost Pool KBM } \\
\text { khusus Kelas III }\end{array}$ \\
\end{tabular} & 121.154 & & & & & 16 & 1.938 .462 & & & & & & \\
\hline & \begin{tabular}{|l|l|}
$\mathrm{d}$ & $\begin{array}{l}\text { Activity Cost Pool KBM } \\
\text { khusus Kelas IV }\end{array}$ \\
\end{tabular} & 215.385 & & & & & & & 18 & 3.876 .923 & & & & \\
\hline & \begin{tabular}{|l|l|} 
e & $\begin{array}{l}\text { Activity Cost Pool KBM } \\
\text { khusus Kelas V }\end{array}$ \\
\end{tabular} & 204.049 & & & & & & & & & 19 & 3.876 .923 & & \\
\hline & \begin{tabular}{|l|l|}
$\mathrm{f}$ & $\begin{array}{l}\text { Activity Cost Pool KBM } \\
\text { khusus Kelas VI }\end{array}$ \\
\end{tabular} & 60.000 & & & & & & & & & & & 14 & 840.000 \\
\hline & \begin{tabular}{|l|l}
$\mathrm{g}$ & Activity Cost Pool \\
Kegiatan seluruh siswa
\end{tabular} & 48.613 & 23 & 1.118 .109 & 29 & 1.409 .790 & 16 & 777.815 & 18 & 875.042 & 19 & 923.655 & 14 & 680.588 \\
\hline & \begin{tabular}{|l|l}
$\mathrm{h}$ & Activity Cost Pool Seluruh \\
Siswa Berdasarkan \\
Aktivitas Sekolah \\
dialokasikan ke Jumlah
\end{tabular} & 1.098 .965 & 23 & 25.276 .184 & 29 & 31.869 .972 & 16 & 17.583 .433 & 18 & 19.781 .362 & 19 & 20.880 .326 & 14 & 15.385 .504 \\
\hline 3 & \multicolumn{2}{|c|}{ Jumlah Biaya Keseluruhan dalam 1 Tahun } & & 124.226.161 & & 216.443 .498 & & 114.398 .248 & & 118.631 .865 & & 132.748 .049 & & 109.314 .573 \\
\hline 4 & \multicolumn{2}{|c|}{\begin{tabular}{|c|} 
Jumlah Siswa Per Tingkat \\
\end{tabular}} & & 23 & & 29 & & 16 & & 18 & & 19 & & 14 \\
\hline 5 & \multirow{2}{*}{\multicolumn{2}{|c|}{\begin{tabular}{|l|} 
Biaya Satuan Pendidikan Siswa Per Tahun \\
Biava Satuan Pendidikan Siswa Per Bulan
\end{tabular}}} & & 5.401 .137 & & 7.463 .569 & & 7.149 .891 & & 6.590 .659 & & 6.986 .739 & & 7.808 .184 \\
\hline 6 & & & & 450.095 & & 621.964 & & 595.824 & & 549.222 & & 582.228 & & 650.682 \\
\hline
\end{tabular}


Dari tabel dan grafik diatas dapat diketahi bahwa biaya yang dialokasikan ke kelas II adalah biaya yang paling tinggi jika dibandingkan dengan kelas lain, hal ini dikarenakan jumlah rombongan belajar dan jumlah siswa yang ada di kelas II lebih banyak dari pada jumlah rombel dan siswa kelas lainnya. Kemudian kita juga bisa mengetahui bahwa walaupun aktivtas khusus kelas VI lebih banyak dari kelas lainnya, namun aktivitas aktivitas khusus kelas VI bukanlah aktivitas yang memerlukan biaya yang tinggi, hal ini juga dipengaruhi oleh jumlah siswa kelas VI yang jumlahnya paling sedikit dari jumlah siswa kelas lainnya. Kemudian, walaupun terdapat beberapa aktivitas khusus untuk kelas VI, namun juga terdapat aktivitas yang dikurangi, contohnya aktivitas ekstrakurikuler, bagi tingkat lainnya biaya ekstrakurikuler dikeluarkan untuk satu tahun ajaran penuh, namun untuk kelas VI biaya ekstrakurikuler hanya dikeluarkan untuk satu semester saja.

Dari grafik tersebut dapat diketahui bahwa biaya satuan pendidikan kelas VI merupakan biaya yang paling besar disbanding dengan kelas lain meskipun biaya alokasi pendidikan per tahunnya merupakan yang paling rendah. Hal ini disebabkan jumlah siswa kelas VI adalah jumlah siswa yang paling sedikit.

Komparasi Biaya Satuan Pendidikan Menggunakan Metode Tradisional dan Metode Activity Based Costing

\begin{tabular}{|c|l|lr|ll|}
\hline No & \multicolumn{1}{|c|}{ Kelas } & \multicolumn{2}{|c|}{ Metode Tradisional } & \multicolumn{2}{c|}{ Metode ABC } \\
\hline 1 & Kelas I & $\mathrm{Rp}$ & 496.184 & $\mathrm{Rp}$ & 450.095 \\
\hline 2 & Kelas II & $\mathrm{Rp}$ & 597.688 & $\mathrm{Rp}$ & 621.964 \\
\hline 3 & Kelas III & $\mathrm{Rp}$ & 582.208 & $\mathrm{Rp}$ & 595.824 \\
\hline 4 & Kelas IV & $\mathrm{Rp}$ & 590.053 & $\mathrm{Rp}$ & 549.222 \\
\hline 5 & Kelas V & $\mathrm{Rp}$ & 572.775 & $\mathrm{Rp}$ & 582.228 \\
\hline 6 & Kelas VI & $\mathrm{Rp}$ & 639.767 & $\mathrm{Rp}$ & 650.682 \\
\hline
\end{tabular}

\begin{tabular}{|l|lr|}
\hline \multicolumn{1}{|c|}{ Kelas } & \multicolumn{2}{c|}{ Selisih Biaya } \\
\hline Kelas I & $\mathrm{Rp}$ & 46.089 \\
\hline Kelas II & $-\mathrm{Rp}$ & 24.277 \\
\hline Kelas III & $-\mathrm{Rp}$ & 13.616 \\
\hline Kelas IV & $\mathrm{Rp}$ & 40.832 \\
\hline Kelas V & $-\mathrm{Rp}$ & 9.454 \\
\hline Kelas VI & $-\mathrm{Rp}$ & 10.915 \\
\hline Sumber : Data diolah
\end{tabular}

Dari keenam tabel tersebut, dapat diketahui bahwa perhitungan biaya satuan pendidikan menggunakan metode ABC tidak selalu lebih besar ataupun lebih kecil darpada perhitungan menggunakan metode tradisional.
Selisih positif pada ketiga tabel diatas menunjukan adanya overcosting perhitungan metode tradisional, dan selisih negative menunjukan adanya undercosting perhitungan metode tradisional.

Undercosting dan overcosting perhitungan metode tradisional terjadi karena metode tradisional hanya membebankan biaya dengan dasar alokasi jumlah siswa, hal ini dapat menyebabkan biaya aktivitas khusus tingkat kelas tertentu ditanggung oleh tingkat kelas lainnya.

\section{KESIMPULAN}

Berdasarkan penelitian yang dilakukan dapat ditarik beberapa kesimpulan sebagai berikut :

1. Biaya satuan pendidikan (educational unit cost) per tingkat dan kelas pada SDI Attaqwa yang dihitung menggunakan metode tradisional adalah sebagai berikut, kelas I Rp 496.184, kelas II Rp 597.688, kelas III Rp 582.208, kelas IV Rp 590.053, kelas V Rp 572.775, dan kelas VI Rp 639.767.

2. Biaya satuan pendidikan (educational unit cost) per tingkat dan kelas pada SDI Attaqwa yang dihitung menggunakan metode activity based costing adalah sebagai berikut, kelas I Rp 450.095, kelas II Rp 621.964, kelas III Rp 595.824, kelas IV Rp 549.222, kelas V Rp 582.228, dan kelas VI Rp 650.682.

3. Selisih biaya satuan pendidikan (educational unit cost) per tingkat dan kelas pada SDI At-taqwa yang dihitung menggunakan metode tradisional dan metode activity based costing adalah sebagai berikut, kelas I terjadi overcost sebesar Rp 46.089, kelas II terjadi undercost sebesar Rp 24.277, kelas III terjadi undercost sebesar Rp 13.616, kelas IV terjadi overcost sebesar Rp 40.832, kelas $\mathrm{V}$ terjadi undercost sebesar $\mathrm{Rp}$ 9.454, dan kelas VI terjadi undercost sebesar Rp 10.915. Undercost dan overcost yang terjadi dikarenakan adanya perhitungan perbandingn antara kedua metode.

4. Selisih biaya satuan pendidikan yang dihitung dengan metode activity based costing tidak selalu lebih besar ataupun lebih kecil. Tetap terjadi adanya undercosting dan overcosting atas perhitungan metode tradisional, hal ini 
disebabkan karena biaya tidak dibebankan berdasarkan aktivitas masing-masing tingkat dan kelas. Sehingga memungkinkan terjadinya pembebanan biaya ke seluruh atau sebagian siswa atas biaya aktivitas kelas tertentu.

5. Dalam pelaksanaan kegiatan sekolah, SDI At-taqwa mengalokasikan dananya secara signifikan ke dalam aktivitas belajar mengajarnya, yaitu sebesar $58 \%$.

6. Pembebanan biaya yang dilakukan dengan metode tradisional hanya menggunakan basis jumlah siswa keseluruhan dan jumlah siswa per kelas saja. Sedangkan dalam metode $\mathrm{ABC}$, dasar pembebanan biaya yang dilakukan lebih bervariasi, sesuai dengan pemicu dan satuan penyebab timbulnya biaya aktivitas tertentu, dalam metode $\mathrm{ABC}$ juga dilakukan pembebanan biaya antar aktivitas.

\section{SARAN}

Berdasarkan penelitian yang telah dilakukan, penulis memberi saran untuk pihak sekolah dan untuk penelitian selanjutnya, diantaranya adalah berikut:

1. Bagi SDI At-taqwa Bekasi

a. Hasil perhitungan biaya satuan pendidikan dengan menggunakan metode activity based costing dapat dipergunakan sebagai dasar pertimbangan pelaksanaa perencanaan dan evaluasi dalam menyusun RKAS tahun ajaran yang akan datang.

b. Sekolah dapat menetapkan biaya satuan pendidikan yang berbeda pada setiap tingkatan kelas tergantung biaya aktivitas yang sesungguhnya terjadi pada tingkat kelas tertentu agar tidak terjadi undercosting ataupun overcosting.

c. Apabila pihak sekolah ingin mempertimbangkan untuk menggunakan metode activity based costing, sekolah disarankan mempunyai informasi yang detil mengenai pemasukan dan pengeluaran sekolah diluar dana pendidikan yang didapat dari pemerintah, baik BOSNAS ataupun BOSDA. Guna mengetahui detil biaya yang benarbenar dibebankan kepada orangtua murid sehingga tidak terjadi undercosting ataupun overcosting

\section{DAFTAR PUSTAKA}

Azizah, K., \& Sukirno, S. (2016). Analisis Satuan Biaya Pendidikan Menengah Kejuruan Di Smk Negeri 1 Depok Sleman. Kajian Pendidikan Akuntansi Indonesia, 5(1).

Bastian, I. (2015). Akuntansi Pendidikan. Yogyakarta: BPFE.

Bastian, I., \& Idrus, O. (2014). Akuntansi pendidikan. Tangerang: Universitas Terbuka.

Pemerintah Daerah Kota Bekasi. Peraturan Pendidikan (2014).

Dewi, W. S. (2018). Studi Komparasi Perhitungan Biaya Satuan Pendidikan Dengan Menggunakan Metode Tradisional dan Metode Activity Based Costing Pada SMA NEGERI 1 Sleman Tahun Ajaran 2016/2017. Jurnal Akuntansi.

Dwi, R. (2018). Penerapan Activity Based Costing (ABC) untuk Menghitung Biaya Satuan (Unit Cost) pada SMK Negeri 3 Kasihan Bantul. Jurnal Akuntansi.

Kadir, A. (2015). Dasar-Dasar Pendidikan. Jakarta: Kencana.

Purwaji, A., Wibowo, \& Muslim, S. (2016). Akuntansi Biaya (2nd ed.). Jakarta: Salemba Empat.

Slamet, A. (2007). Penganggaran, Perencanaan dan Pengendalian Usaha. Semarang: UNNES Press.

Somantri, M. (2014). Perencanaan pendidikan. Bogor: PT Penerbit IPB Press.

Tanggela, M. (2013). Analisis Implementasi Kebijakan Pengelolaan Sarana dan Prasarana Sekolah Di SMP Negeri 2 Batu. Jurnal Kebijakan Dan Pengembangan Pendidikan, 1(1). 